\title{
Ecological vulnerability of two sea turtle species in the Gulf of Mexico: an integrated spatial approach
}

\author{
Eduardo Cuevas ${ }^{1,2}$, María de los Ángeles Liceaga-Correa ${ }^{1, *}$, \\ Abigail Uribe-Martínez ${ }^{1,3}$ \\ ${ }^{1}$ Departamento de Recursos del Mar,
Centro de Investigación y de Estudios Avanzados del Instituto Politécnico Nacional - Unidad Mérida, PC 97310 Mérida,
Yucatán, México \\ ${ }^{2}$ Present address: CONACYT - Universidad Autónoma del Carmen, Facultad de Ciencias Naturales, \\ PC 24155 Ciudad del Carmen, Campeche, México \\ ${ }^{3}$ Present address: Universidad Autónoma del Carmen, Facultad de Ciencias Naturales, PC 24155 Ciudad del Carmen, \\ Campeche, México
}

\begin{abstract}
Changes in ecological attributes as a result of anthropogenic activities and climatic forces can jeopardize biodiversity, so these potential impacts must be evaluated for conservation. Integrating the different components of a large ecosystem can, however, pose a methodological challenge. When evaluating the sensitivity of a system, the level of stress imposed by a threat and the system's ability to deal with pressures ultimately define its actual condition. The objective of this study was to assemble a spatially explicit quantitative approach for evaluating the ecological vulnerability of 2 sea turtle species (Eretmochelys imbricata and Chelonia mydas). We used a method that combined the use of an open source planning tool (Conservation Action Planning) and spatial multicriteria analysis to determine the total cumulative ecological vulnerability to multiple threats for each species individually and for both species combined. The spatially explicit outputs were supported by hard data and expert knowledge, including the cumulative ecological vulnerability of each species to multiple threats. For each species, we identified areas in the Gulf of Mexico where individual threats have a potential impact and also determined high vulnerability locations. This spatially explicit approach is important when assessing ecological vulnerability and risk, it is versatile and easily reproducible for other organisms, and can be an important tool in supporting the conservation and management of endangered species.
\end{abstract}

KEY WORDS: Hawksbill turtle $\cdot$ Green turtle $\cdot$ Satellite telemetry $\cdot$ Movement ecology $\cdot$ Spatial planning

\section{INTRODUCTION}

Sea turtle species are of great concern in marine environments. The Gulf of Mexico and Caribbean Sea host 5 species, including hawksbill Eretmochelys imbricata, green Chelonia mydas, loggerhead Caretta caretta, Kemp's ridley Lepidochelys kempii and leatherback Dermochelys coriacea turtles (Valverde \& Holzwart 2017). As integral components of these

\footnotetext{
*Corresponding author: maria.liceaga@cinvestav.mx
}

large ecosystems, sea turtles provide important ecological services, such as nutrient transport and recycling, control of populations at lower trophic levels and ecosystem maintenance, among others (Bouchard \& Bjorndal 2000, Heithaus 2013).

Hawksbill and green turtles are important to 2 of the most productive marine ecosystems in the tropics: reefs and seagrass meadows. The Gulf of Mexico harbors the largest nesting population of hawksbill

() The authors 2019. Open Access under Creative Commons by Attribution Licence. Use, distribution and reproduction are unrestricted. Authors and original publication must be credited. 
turtles in the Western Atlantic and the fifth largest nesting population of green turtles (Garduño-Andrade et al. 1999, Spotila 2004, Mortimer \& Donnelly 2008). Evaluating the threats to these sea turtle populations and their habitats (particularly fisheries, climate change and pollution) and understanding the movement of individuals is needed in order to facilitate informed conservation actions. This information is considered a priority in sea turtle conservation and management research worldwide (Jeffers \& Godley 2016, Hays et al. 2019). In this context, it is important to assess the ecological vulnerability of sea turtles to better execute any preventive or emergency measures. These are key species in the ecosystems they occupy, and therefore there is a clear interest in evaluating their vulnerability (Sanderson et al. 2002, Eckert \& Hemphill 2005).

Vulnerability evaluation for a given biological or social entity has been a powerful tool for describing the states of susceptibility and exposure to threats (Adger 2006). For our purposes, we define ecological vulnerability as the result of exposing a sensitive attribute of an object of interest (OI) to a multi-level threat while considering the internal and external capabilities of the OI to cope with the impact (Zacharias \& Gregr 2005, Thiault et al. 2018). In the past decade, several approaches and methods have been proposed to quantitatively evaluate ecological vulnerability (Fuentes et al. 2011, Tolotti et al. 2015, Thiault et al. 2018). Although these methods differ slightly depending on the target of the application, almost all consider the same key parameters: sensitivity, exposure and adaptive capacity (McCarthy et al. 2001). The published methods have employed different quantitative techniques, both with and without explicit spatial modules.

In this study, we used a scheme that combines the evaluation of the impacts of several threats on 2 species of sea turtles in the Gulf of Mexico with spatially explicit information. Our approach in this study, which is the first spatially explicit evaluation of the ecological vulnerability of sea turtles in the region, was based on location data (satellite telemetry) of sea turtle individuals and the threats acting on them and their habitats (using public information and expert knowledge).

To date, most published vulnerability assessments have focused on whole ecosystems or regions of interest, likely masking critical information about the endangered species within those ecosystems. This type of assessment is potentially problematic when the information gathered is explicitly utilized for decision making and management strategies, partic- ularly for species such as sea turtles (Ban et al. 2010). For example, Micheli et al. (2013) evaluated cumulative human impacts on marine ecosystems in the Mediterranean using a weighted cumulative impact on this ecoregion; however, they did not evaluate stability coefficients or adaptive capacity, as suggested by Intergovernmental Panel on Climate Change (IPCC) (Füssel \& Klein 2006). Due to a lack of information on the resistance or resilience capabilities of natural systems, evaluating their stability coefficients or adaptive capacity is rare (Beever et al. 2016); thus, many studies focus only on the potential impacts of multiple threats.

Sea turtles are species of great concern in marine environments in terms of the potential impacts of human and natural threats acting on their populations and critical habitats (Frazier 2005, Mazaris et al. 2017, Valdivia et al. 2019). Nevertheless, there are information gaps in terms of the vulnerability of their populations and aggregation zones (i.e. areas used for reproduction and feeding home ranges). Incorporating different tools for conservation research with spatially explicit strategies will help to integrate the critical information that is needed to implement conservation and management strategies for these endangered species.

The objective of this study was to evaluate the ecological vulnerability of 2 species of sea turtles in the Gulf of Mexico to multiple threats, with the aim of calculating the cumulative ecological vulnerability for both species, determined by building and implementing a spatially explicit approach. This conceptual framework allowed us to successfully use available geographic data (including satellite telemetry records) to generate spatially explicit outputs regarding the sensitivity, potential impacts of several threats, coefficients of stability and ecological vulnerability for these 2 species.

\section{MATERIALS AND METHODS}

\subsection{Study site}

We defined our study area as the reported geographic distribution of hawksbill and green sea turtles in the Mexican waters of the Gulf of Mexico and the Caribbean Sea, an area that includes the Exclusive Economic Zone of Mexico and small portions of other territories (Fig. 1). This study area also contained the habitat suitability range for both species described by Uribe-Martínez et al. (2017), which describe the geographic range of these species in this 


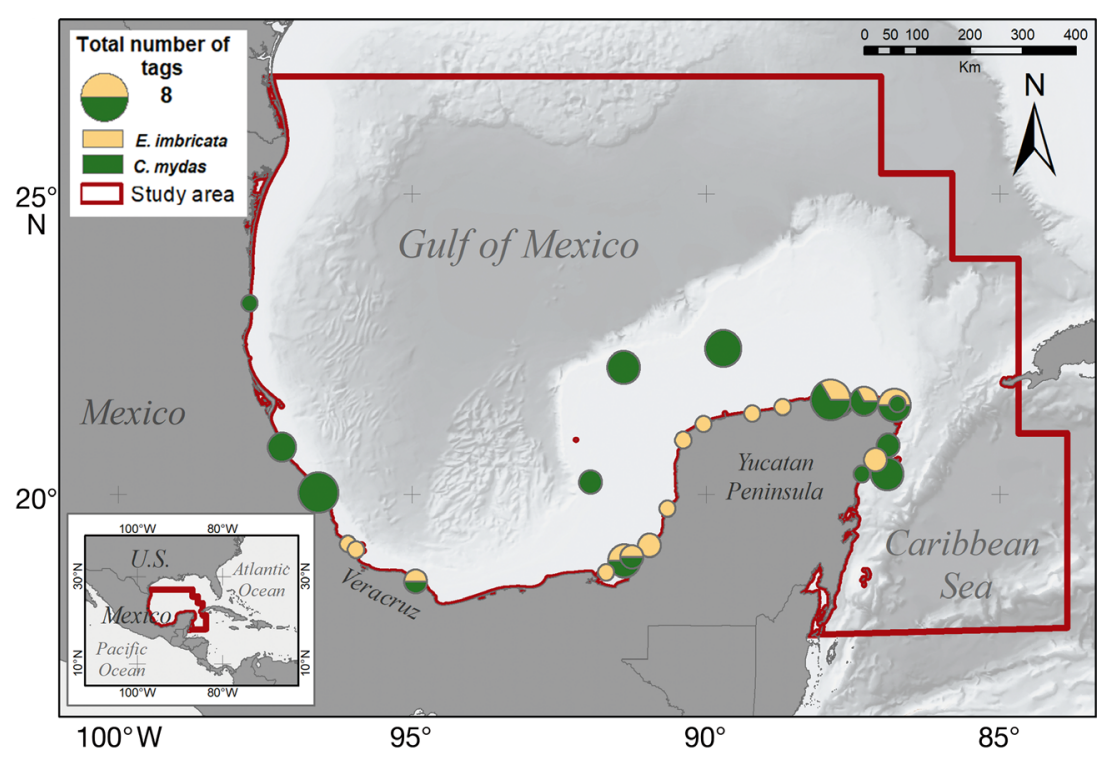

Fig. 1. Analyzed region including the Mexican Exclusive Economic Zone in the Gulf of Mexico and the western Caribbean Sea where the hawksbill Eretmochelys imbricata and green Chelonia mydas sea turtles occur. Pie plots show locations where tags were deployed; the size of the plot reflects the number of tags deployed (max. 8). Gulf of Mexico shaded relief basemap by French \& Schenk (2015); coastlines are from Sandivik (2009) tion components and spatially explicit analysis. The parametrization analysis was based on the Conservation Action Plan (CAP) tool developed by The Nature Conservancy (Granizo et al. 2006, Carr et al. 2017) (https:// www.conservationgateway.org/Conser vationPlanning/ActionPlanning/Case StudiesandPlanExamples/Pages/casestudies-and-plan-exa.aspx). This tool enables integration of scientific data and expert knowledge (Carr et al. 2017) for ecological integrity and threat assessment in order to provide a synoptic panorama of the actual status for the OI. The spatially explicit evaluation employs map algebra operations in geographic information systems to conjugate the terms demanded by the general vulnerability equation (Eq. 1) (Malczewski 1999); this step is recognized as the natural progression for using the CAP tool as a spatially explicit analysis (The Nature Conservancy 2015).

region. Both geographic ranges are included in the Atlantic-Western Caribbean and Atlantic-Northwest regional management units for hawksbill and green turtles, respectively (Wallace et al. 2010). Our study area is also framed within the South Florida/ Bahamian Atlantic, Southern Gulf of Mexico and Caribbean Marine Ecoregions of North America (Wilkinson et al. 2009).

The study species (hawksbill and green sea turtles) were selected because they are species with clear engineering roles in the marine ecosystems they occupy (Jackson 1997, Turner \& Klaus 2005, Lal et al. 2010, Heithaus 2013) and data were available at the time of this analysis.

\subsection{Ecological vulnerability assessment}

We defined 'ecological vulnerability' as the condition in which at least one sensitive attribute of an OI (in this case, hawksbill and green turtles) is exposed to a multi-level threat (modified from Zacharias \& Gregr 2005). Within this definition, we integrated complementary quantitative elements into a utility model for an ecological vulnerability evaluation (Fuentes et al. 2011, Thiault et al. 2018).

This methodological approach includes 2 complementary steps: parametrization of vulnerability equa-
Based on this approximation, we followed a conceptual framework in which we (1) quantified the sensitivity of the 2 sea turtle species based on satellite telemetry data, (2) evaluated the potential impacts of individual in-water threats to their populations and habitats, (3) considered the action of a stability coefficient through intrinsic and extrinsic factors, (4) calculated the ecological vulnerability of each sea turtle species to individual threats and (5) quantified their cumulative ecological vulnerability based on the individual assessments.

The calculation of the OI's vulnerability to a specific threat $\left(\operatorname{Vuln}_{\mathrm{Th}}\right)$ is mathematically expressed as:

$$
\text { Vuln }{ }_{\mathrm{Th}}=\text { Sens } \times \operatorname{Exp}_{\mathrm{Th}}-\mathrm{SC}
$$

where Sens is sensitivity, $\operatorname{Exp}_{\mathrm{Th}}$ is exposure to a threat and SC is the stability coefficient of the sea turtle population (modified from Füssel \& Klein 2006, Fuentes et al. 2011). Each of these terms is explained in the following paragraphs.

\subsection{Conceptual framework and parametrization of this approach}

Here, we considered sea turtles as OIs characterized by their attributes, which are the dominant ecological features that are critical to their ecological 
integrity. Thus, if these attributes are negatively impacted or disturbed to the point whre it impacts survival, the OI might disappear (modified from Granizo et al. 2006). These attributes are directly linked to indicators that are quantifiable variables and can be mapped under the approach proposed in this study. We used satellite tracking data to define the attributes of the OI, in this case their home ranges during the internesting, migration and feeding phases of their life cycle.

We applied map algebra for the vulnerability assessment under this spatial multicriteria decision analysis approach. For all indicators, SMART+ criteria (specific, measurable, achievable, relevant and timebound + availability of their spatial representation) were considered (Granizo et al. 2006, Carr et al. 2017).

Ecological vulnerability was evaluated within discrete spatial units that were defined as a regular lattice of hexagons covering the entire study area. Hexagons are convenient for representing neighborhoods and connectivity, and they can be adjusted to spatially evaluate large areas as well as combinations of multi-resolution data sources (Birch et al. 2007). In this case, hexagons with diameters of $25 \mathrm{~km}$ were used $\left(405.95 \mathrm{~km}^{2}\right)$, which encompassed the spatial resolution of the data available for the indicators of all vulnerability terms.

To maintain mathematical consistency in the calculations, all variables were rescaled from 0 to 1 when summed for each term in Eq. (1); in this manner, the range of values was kept the same for all variables in the solved equations.

\subsubsection{Sensitivity}

The first term in Eq. (1), sensitivity, refers to the degree to which the attributes of the OI are impacted by a specific threat, considering their associated indicators (Fuentes et al. 2011). This term is associated with the ecological integrity of the OI (Granizo et al. 2006), which is defined as the ability of an ecological system to withstand perturbations and maintain a healthy condition within natural ranges of variation (adapted from Parrish et al. 2003).

Under the conceptual premise that sensitivity to threats increases as the ecological integrity (viability) of an OI diminishes (Reza \& Abdullah 2011), we evaluated sensitivity as having an ecologically inverse relationship with the viability of the OI. This term can be viewed as the response to the question as to the attributes impacted or modified by the assessed threats.

$$
\text { Sens }=\sum_{i} \lambda_{j} \mathrm{Att}_{i}
$$

where each attribute indicator $\left(\mathrm{Att}_{i}\right)$ has an assigned $\lambda_{i}$ that weights the attributes.

Using the CAP tool, we evaluated the ranks of the sensitivity of the OIs and built the first term of the vulnerability equation. Satellite tracking is an expensive technology for defining the spatial and movement ecology of large marine organisms; however, its efficiency has been widely proven (Hays \& Hawkes 2018). From existing literature (GonzálezGarza et al. 2015, del Corral-Mancera 2016, Labastida-Estrada et al. 2019), we evaluated individuals from 9 green turtle and 12 hawksbill turtle rookeries. Additionally, Jeffers \& Godley (2016) showed that only $3 \%$ of published papers tracked more than 70 sea turtle individuals; thus, our study based on the locations of 65 adult reproductive females of both species captured during their nesting season (43 for Chelonia mydas and 22 for Eretmochelys imbricata) using satellite telemetry data (permit from SGPADGVS/SEMARNAT, Mexico, No. 09583/15), includes a sufficient number of tracked individuals to infer the populationlevel distribution, as indicated by Schofield et al. (2013). The number of tracked individuals in the present study was significantly larger than other tracking projects around the world (Jeffers \& Godley 2016), and adult reproductive females were used as the life stage to study because nesting females are critical for the recovery of populations worldwide (Heppell 1998).

We considered adult reproductive females as a compact life stage focus group. Variability in somatic and ethological conditions within the group was expected but did not affect the general representation of their spatial distribution and configuration. Additionally, as sea turtles are loyal to their nesting beaches (thus their internesting sites), feeding grounds (even overwintering) and migratory routes (philopatry) (Broderick et al. 2007, Hulin \& Guillon 2007, Lee et al. 2007, Stiebens et al. 2013, Gaos et al. 2017), we assumed that the spatial configuration elucidated by the tracked individuals from several beaches in the study area was valid and representative of the nesting female populations in the study region, thus incorporating a connectivity element (migratory routes) as has been encouraged to enable better conservation plans (Mazor et al. 2016).

The tracking data were quality-controlled by running a speed-distance filter ('vmask') algorithm (implemented in R 'argosfilter' package; Freitas et al. 
2008), and any record on land was deleted, using the mask from Global Administrative Areas (https:// gadm.org/). The data were then visually semi-quantitively classified as belonging to the internesting, foraging or migration periods. Note that we had the complete track of each individual when this stage of classification was done, so the full spatial configuration and behavior of the individual was available for analysis. The first ecological attribute (internesting period) was defined by the location of the tracked females during the period in which they stayed near their nesting beaches between consecutive egg-laying events, spatially circumscribing a well-defined region close to shore in which all location records overlapped (as previously described by Tucker et al. 1995) (Table 1).

The second attribute was built with the tracking data during the individuals' feeding/long-term aggregations. These were defined once a female restricted her movements (known from telemetry data) to a defined space, in which she remained for years while preparing for the next reproductive season, and where all location records overlapped and clustered in the area each individual delimited. Kernel utilization distributions (KUDs) were calculated using the function 'kernelUD' implemented in R package 'adehabitatHR' (Calenge 2006). These were calculated for every individual in each of the 2 abovementioned stages, with a spatial resolution of $1 \mathrm{~km}$ and a smoothing factor $(h)$ calculated using the ad hoc method (Worton 1989). Home ranges were obtained based on the $80 \%$ isopleth of each KUD (Calenge 2006). We then merged individual home ranges for both types of aggregation area (internesting and feeding/long-term periods) to obtain a single layer for both stages for each species.

The third ecological attribute of sensitivity is the connectivity between the internesting and feeding habitats, which is essential for migration. Only those records gathered during migration periods were used to count the number of individuals which migrated through each spatial evaluation unit (hexagon), and were attributed to each corresponding unit. This procedure was done for the migratory records of each species derived from the satellite tracking data sets, using the day after the last record in the area of interest, and until the second day when the individual entered the feeding/residence area spatially delimited by the location records at this stage.

The weights of the stages ( $\lambda_{i}$ in Eq. 2) were 0.6 for long-term aggregations (feeding), 0.3 for internesting areas and 0.1 for migratory routes (modified from Cuevas et al. 2018a). The main indicator for these weights was the time spent during each stage at a given site. For instance, in long-term aggregations, individuals may stay for $2-3 \mathrm{yr}$, whereas migration sites are occupied for only a short period as the individuals pass by; however, without those critical migratory sites, sea turtles would not be able to complete their life cycle.

Additionally, to obtain tabular outputs of the sensitivity of the discrete categories (Table 1), we used the Jenks method to maximize variability between categories and minimize variability within categories (North 2009), using the minimum and maximum values for each attribute (KUD kernels and migration site usage) as the domain range for our analysis.

\subsubsection{Exposure}

The second term in Eq. (1), exposure, quantifies the occurrence of a threat that negatively affects the attribute(s) of the OI with variable intensity. This threat is defined by 3 features according to the CAP tool analysis approach: severity, scope and irre-

Table 1. Indicators of the ecological attributes used for the sensitivity term in the vulnerability assessment of hawksbill Eretmochelys imbricata and green Chelonia mydas sea turtles in the Gulf of Mexico and western Caribbean. Values ranged from 0 to 1 depending on the frequency distribution of the input data in the layers, and the sensitivity categories were assigned using the Jenks method. Procedures for determining indicators are presented in Section 2.3.1

\begin{tabular}{|c|c|c|c|c|c|c|}
\hline Ecological attribute & Category & Indicator & Very high & High & Fair & Very low \\
\hline $\begin{array}{l}\text { Aggregation of in-water } \\
\text { reproductive females }\end{array}$ & Population size & $\begin{array}{l}\text { Sum of the kernel } \\
\text { utilization densities }\end{array}$ & 0.1214 & 0.2929 & 0.5357 & 1.0000 \\
\hline $\begin{array}{l}\text { Feeding/long-term } \\
\text { aggregations }\end{array}$ & Population size & $\begin{array}{l}\text { Sum of the kernel } \\
\text { utilization densities }\end{array}$ & 0.2150 & 0.4750 & 0.8000 & 1.0000 \\
\hline $\begin{array}{l}\text { Spatial connectivity for } \\
\text { migration between } \\
\text { critical habitats }\end{array}$ & $\begin{array}{l}\text { Landscape } \\
\text { context }\end{array}$ & $\begin{array}{c}\text { Number of individuals } \\
\text { using each } \\
\text { hexagon for migration }\end{array}$ & 0.1493 & 0.3765 & 0.6924 & 1.0000 \\
\hline
\end{tabular}


versibility. Severity is the degree or intensity of the damage caused by the threat in a location; scope is the geographic extent of the threat in the study area; irreversibility is a measure of whether the negative impact may or may not be reversed (Granizo et al. 2006). The CAP tool platform was used to rank the threats based on a hierarchical process.

The sensitivity of an OI to the intensity of the interaction with a specific threat is termed the potential impact $\left(\mathrm{PI}_{\mathrm{Th}}\right)$, and it is mathematically expressed as:

$$
\mathrm{PI}_{\mathrm{Th}}=\text { Sens } \times \operatorname{Exp}_{\mathrm{Th}}
$$

The threats used in this assessment were selected from the Program of Actions for the Conservation of Species (PACE in Spanish) for E. imbricata and C. mydas (Comisión Nacional de Áreas Naturales Protegidas 2009, 2011, Secretaría de la CIT 2010). A total of 6 in-water threats were identified and quantified by experts in terms of their severity, scope and irreversibility. We also collaborated in a workshop (in 2018) with more than 20 sea turtle conservation and monitoring experts from Mexican institutions that have studied nesting beaches and in-water critical habitats for 5-30 yr in Mexico. Workshop participants came from federal, state and municipality agencies, as well as nongovernmental organizations, universities and research institutes, all of which were active practitioners of sea turtle monitoring, conservation, management and research in Mexico.

Through group dynamics, the experts ranked the threats using the CAP tool rationale in terms of their severity (magnitude and strength of the impact on sea turtle populations and their habitats), scope (geographic coverage of the threat, including whether it is punctual or impacts a wide geographic range) and irreversibility (in time, how irreversible the threats are, and if their reversibility is feasible); moreover, combined with the analytic hierarchy process (Saaty 2008, Goepel 2013), a numeric weight was assigned to each threat (Table 2). In this approach, we included a sense of time and space in the qualification of threats while updating and validating the in-water threats used in this analysis (Fig. S1 in the Supplement at www.int-res.com/articles/suppl/n040p337_ supp.pdf).

The first identified threat was sea turtle bycatch, and a modification of catch per unit effort (CPUE) reported by Cuevas et al. (2018a) was selected as an indicator of fishing intensity in the study area for the quantitative assessment. The spatial layer was built using historical data summarized over $10 \mathrm{yr}$ from the National Yearbooks of Fisheries in Mexico and the National Fishing Chart (Diario Oficial de la Federación 2012), as well as from the available literature on fishing effort in the Gulf of Mexico (Noguez Fuentes et al. 2007). We included data from tuna, shrimp and multi-species fisheries (snapper, mackerel, mullet, grouper, sea bass, tarpon, saw fish and sea trout), as they are fished using longlines, gillnets and trawl nets. Due to differences in the data sources, we assembled the data in a fishery-intensity index that considered different weights for the type of fishing gear and the length of vessels used, multiplied by the number of vessels and the last $10 \mathrm{yr}$

Table 2. Indicators of threats used for the exposure term in the ecological vulnerability assessment of hawksbill and green turtles in the Gulf of Mexico and Western Caribbean. The selected threats were taken from published documents, and the quantitative values were obtained through interviews with experts and by using the analytic hierarchy process. Procedures for determining indicators are presented in Section 2.3.2. SST: sea surface temperature

\begin{tabular}{|c|c|c|c|c|c|}
\hline \multirow[t]{2}{*}{ Threat } & \multirow{2}{*}{ Indicator } & \multicolumn{4}{|c|}{ - Hawksbill and green turtles } \\
\hline & & Severity & Scope & Irreversibility & $\begin{array}{l}\text { Hierarchical value } \\
\text { (weight) }\end{array}$ \\
\hline Fishing effort & Index of fishing intensity & High & High & High & $\begin{array}{l}\text { High } \\
(0.481)\end{array}$ \\
\hline Increase in average SST & $\begin{array}{l}\text { Long-term trend of average } \\
\text { SST (2003-2016) }\end{array}$ & Medium & High & High & $\begin{array}{l}\text { Medium } \\
(0.142)\end{array}$ \\
\hline Occurrence of hurricanes & $\begin{array}{l}\text { Frequency and intensity of } \\
\text { hurricanes }\end{array}$ & Medium & High & High & $\begin{array}{l}\text { Medium } \\
(0.118)\end{array}$ \\
\hline Cargo vessel transit & Large vessel transit intensity & Low & High & High & $\begin{array}{l}\text { Low } \\
(0.116)\end{array}$ \\
\hline $\begin{array}{l}\text { Impacts by oil extraction } \\
\text { platforms }\end{array}$ & Location of platforms & Medium & Low & High & $\begin{array}{l}\text { Low } \\
(0.088)\end{array}$ \\
\hline Seismic surveys & $\begin{array}{l}\text { Polygons with permits for } \\
\text { exploratory surveys }\end{array}$ & Low & High & High & $\begin{array}{l}\text { Low } \\
(0.054)\end{array}$ \\
\hline
\end{tabular}


annual mean production per capture group (Diario Oficial de la Federación 2012, Comisión Nacional de Acuacultura y Pesca 2014). The final fishing intensity values were established between 0 and 1 in an integrated, unique hexagonal lattice.

The next identified threat was variation in sea surface temperature (SST). This factor is considered to be one of the most important climatic threats affecting sea turtle populations and habitats, as it can disrupt reproductive rhythms (phenology), affect individual fitness and change spatial and temporal distributions (Hawkes et al. 2009, Hamann et al. 2013, Patrício et al. 2019). Moreover, there is evidence of the impact of SST variations on the evaluated hawksbill populations (Álvarez-Acosta 2016). The indicator was the trend (the slope of a linear model) in SST in the study area over the past $14 \mathrm{yr}$, which was determined using MODIS satellite imagery data from 2003 to 2016 (OBPG 2018). The response curves of both species to SST (Uribe-Martínez et al. 2017) were used to define the range of values for ranking adequate and poor SST conditions for these species. The trend values were again transferred to a hexagonal lattice with rescaled values (0 to 1 ).

Another threat to sea turtles is the occurrence of hurricanes in the region. We used layers downloaded from NOAA's website (NOAA 2017) and from the National Meteorological Service in Mexico (Servicio meteorológico nacional 2018) that included tropical storms and hurricanes from 1851 to 2016. Although hurricanes may not be a direct threat to individual survivorship, they have been accepted as an issue of concern at the population and community levels because of the effect they have on sea turtle habitat and thus on their fitness and reproductive rhythms (Fuentes \& Abbs 2010, Dewald \& Pike 2014). Regionally, it has been documented that hurricanes result in alterations to the benthic ecosystems in which the sea turtles feed (Cuevas 2004, Arellano-Méndez et al. 2011). Although hurricanes are natural and seasonal, they are recognized as a threat by the information sources we consulted (literature and experts), so we included them as part of the multi-threat scenario faced by sea turtles (although they are not one of the determinant factors, as indicated by the impact weight). Each line segment of a storm track was classified according to the Saffir-Simpson scale, and ordinal weights from 1 to 6 were assigned to each of the storm categories, from lowest (1: tropical storms) to highest (6: category 5 hurricanes). A decay buffer was generated for the trajectories of the hurricanes with $10 \mathrm{~km}$ steps up to $40 \mathrm{~km}$ (Dewald \& Pike 2014). Each step was assigned a weight value of $1,0.75,0.5$ or 0.25 , from the closest to the farthest (adapted from Zacharias \& Gregr 2005). A rescaled sum (0 to 1) of all intersecting buffer polygons in a hexagon was calculated to obtain a single layer as an indicator of the impact of hurricanes in the southern Gulf of Mexico.

The transit of vessels in the Gulf of Mexico was also considered a threat to sea turtles and their habitats because of the possible perturbations to turtle migration routes and reproductive aggregations, in addition to direct turtle strikes. We accessed data on cargo vessel density in the region from the Department of Commerce through NOAA's Office for Coastal Management, for 2011 and 2013 (ftp://ftp.coast.noaa.gov/pub/ MSP/2011AIS/GulfofMexicoVesselDensity2011.zip). These data were used as an indicator, and their density values were transferred to the hexagonal lattice and rescaled from 0 to 1 .

The location and influence of platforms and fields leased for hydrocarbon extraction were also identified as a threat to the sea turtles. We obtained the locations of active wells in the study area and found a total of 556 platforms (Comisión Nacional de Hidrocarburos 2017a). We defined a $30 \mathrm{~km}$ buffer of influence for each platform (modified from Zacharias \& Gregr 2005, Hu et al. 2009). We also obtained polygons of the oil extraction fields designated by the Mexican Government from the Mexican National Hydrocarbons Commission (Comisión Nacional de Hidrocarburos 2017b). We assigned distinct weights to the platforms (active or on standby) and the class of each field (for offer, contracted or planned). These values were also included as a layer of the hexagonal lattice.

Finally, seismic surveys associated with the oil industry were also considered a threat in this evaluation. Seismic surveys have been highly controversial because of their potential impact on marine fauna, particularly sea turtles and marine mammals (Nelms et al. 2016). We included polygons where seismic surveys had been performed, and we assigned distinct impact values to the areas depending on the technology that was used (air guns for 2and 3-dimensional [2D and 3D] studies or magnetism), with 3D studies having the highest values and magnetism the lowest (Comisión Nacional de Hidrocarburos 2017c).

\subsubsection{Stability coefficient}

The third term of Eq. (1), SC, refers to the stability capacity (modified from Zacharias \& Gregr 2005) and is defined as the intrinsic (structural or func- 
tional features of the individual by itself) or extrinsic (environmental or anthropogenic features linked to the individual) conditions of the OI that promote a tendency to attain or maintain certain suitable conditions for survival and development. We selected a set of conditions that had been documented to contribute to the stability of each OI when facing different threats (Hyrenbach et al. 2000, Scott et al. 2012).

The identified stability conditions for the evaluated threats were represented by both intrinsic and extrinsic features of the sea turtle populations and their habitats (Table 3). The first stability coefficient was identified as natural protected areas (NPAs), which are considered an extrinsic condition that diminishes the impacts of vessel traffic, fishing effort, seismic surveys and hydrocarbon platforms. We included a total of 19 NPAs in different conservation categories (Table S1), classified according to the level of restriction (Diario Oficial de la Federación 2014).

The second indicator was a set of safeguard areas decreed by the Mexican government around the coral reefs and rocky reefs in the Bank of Campeche and the Mexican Caribbean. This executive order by the President prohibits any oil exploration or exploitation activity inside the safeguard polygons (Diario Oficial de la Fedración 2016). The positive contribution of this feature to the OI was considered only for seismic surveys and oil extraction platforms.

The third and final indicator was an intrinsic indicator attributable to the regional trends in the sea turtle population. As a nesting population declines, its extinction risk increases, and it could be inferred that the population and genetic viability decrease at the same rate. Each feeding aggregation area identi- fied according to the analyzed satellite tracking data was linked to its particular nesting population. Therefore, the trends (slope of a linear regression model) in the different nesting areas we studied were used to quantify a mean indicator value for the linked feeding/long-term aggregation areas. We used publicly available data for the indicator of nesting activity per beach from The State of the World's Sea Turtles (SWOT; http://seamap.env.duke.edu/swot), and completed an estimated time series for key nesting beaches using historic data reported for Mexican nesting beaches (Cuevas et al. 2018b).

The areas that harbored individuals from nesting grounds with positive nesting trends received a higher stability coefficient value than the areas that harbored populations with negative nesting trends.

The values of the stability coefficients represent the efficiency with which an OI would address a specific threat according to the indicators, and they were standardized to values from 0 to 0.35 . We used these values based on the literature about the reported efficiency of those positive features to contend with a certain threat (Walters 2000, Christie \& White 2007, Dalton \& Jin 2010) (Fig. S2). It is important to recall the versatility that the approach in this analysis has, to allow weights different from those in the present case to be used (including the efficiency values that were used).

\subsection{Cumulative ecological vulnerability assessment}

Biodiversity is usually subjected to a cumulative effect by multiple threats at the same time, affecting its ecological integrity and viability (Halpern et al. 2008, Halpern et al. 2015, Tulloch et al. 2015).

Table 3. Indicators for stability coefficients used for the ecological vulnerability assessment of hawksbill and green turtles in the Gulf of Mexico and the Western Caribbean. All stability coefficients had the same maximum weighting factor (35\%). Data sources are presented in Section 2.3.3

\begin{tabular}{|lll|}
\hline Threat & Stability coefficient & Indicator \\
\hline Fishing effort & Natural Protected Areas (NPAs) & Polygons of the decreed NPAs \\
& No-take marine reserves (NTMRs) & Polygons of the decreed NTMRs \\
Occurrence of hurricanes & Population size trend & Location of indexed feeding grounds \\
Cargo vessel transit & NPAs & Polygons of the decreed NPAs \\
Seismic surveys & NPAs & Polygons of the decreed NPAs \\
& Safeguards & Polygons of the decreed safeguards \\
Impacts from oil & NPAs & Polygons of the decreed NPAs \\
extraction platforms & Safeguards & Polygons of the decreed safeguards \\
Increase in average sea & Population size trend & Location of indexed feeding grounds \\
surface temperature & & \\
\hline
\end{tabular}




\subsubsection{Ecological vulnerability per species}

Because the OI may be exposed to $m$ number of threats, cumulative vulnerability is defined as the sum of its vulnerabilities to each weighted threat:

$$
\text { Ac.VulnOI }=\sum_{j=1}^{m} \mu_{j} \times \text { VulnTh }_{j}
$$

where $\operatorname{VulnTh}_{j}$ is the vulnerability to threat $j$ (defined by Eq. 1 ), and $\mu_{j}$ is the weight assigned to the specific threat, $j$.

After acquiring all the spatially explicit quantitative representations of sensitivity, the exposure to each threat and the respective stability coefficients, we solved Eq. (1) for each hexagon in the lattice. We obtained 12 ecological vulnerability outputs for the sea turtles, 1 per species for each of the 6 identified threats.

We proceeded to calculate cumulative vulnerability (Eq. 4), which uses the specific weight of each threat to hierarchize the cumulative potential impact on the ecological attributes of the OIs. As all the inputs for Eq. (1) were rescaled before being entered into the equation, the obtained vulnerability index values were comparable among threats, where 0 is no vulnerability, and 1 is the maximum vulnerability value for that threat in the study area. In this manner, the cumulative vulnerability of 1 OI to multiple weighted threats was obtained.

\subsubsection{Multispecies ecological vulnerability}

Once the cumulative vulnerability of several OIs has been determined, the total cumulative vulnerability for a group can be obtained:

$$
\text { Total Ac.Vuln }=\sum_{i=1}^{m} \gamma_{i} \times \text { Ac. VulnOL }_{i}
$$

where $\gamma$ is the weight assigned to an OI based on its relative importance among the evaluated biota. As mentioned above, because all the indicators were normalized and rescaled, all vulnerability measures were comparable. We used Eq. (5) to perform a final calculation in order to obtain the total cumulative vulnerability of the 2 turtle species to the multiple threats identified. This last equation provides the option of weighting the vulnerability of the different OIs because one OI may be considered more important than the others; in this analysis, both OIs were weighted the same (i.e. 1) (Granizo et al. 2006, Thiault et al. 2018). This result represents the final value of the ecological vulnerability of sea turtles in the Gulf of Mexico and the Mexican Caribbean.

\subsection{Variability in ecological vulnerability quantification}

To assess the variance in the ecological vulnerability values under different weights for the major threat (fishing effort) as a proxy of the sensitivity in this analysis, we tested 30 different weighting values for fishing effort in the quantification of the cumulative vulnerability for C. mydas. Fishing effort values from 0.2 to 0.5 (in 0.01 steps) were assigned, while always maintaining the hierarchy of threat importance. Considering that the original value of this threat was 0.481 , the differences in the assigned values were added in equal portions to the rest of the threats, and when the tested value was higher, the difference was equally subtracted from the values of the other threats.

We mapped the spatial configuration of cumulative vulnerability under each of the tested scenarios, and central and dispersion statistics for all mapped values were then plotted and mapped.

\section{RESULTS}

As the result of an integrated assessment that merged different methods, we obtained spatially explicit quantitative representations of the sensitivity and vulnerability of 2 species of sea turtles to 6 different in-water threats in the Gulf of Mexico. The quantitative spatial evaluation of attributes, threats and stability coefficients together with the following results provides a measure of the ecological vulnerability of sea turtle populations and their aggregation areas.

\subsection{Spatial distribution of sensitive features}

The spatial distribution of the sensitivity indicators for hawksbill and green turtles extended primarily over the continental shelf in the Gulf of Mexico (Fig. 2). The most sensitive areas were close to the north and west shorelines of the Yucatan Peninsula, as well as along the northeastern border of the Yucatan shelf. In Veracruz, a few small areas with high sensitivity values were identified that were associated with reproductive aggregations (Fig. 2a,b).

\subsection{Potential impacts}

The 6 identified threats and their spatial interactions with the sea turtles in the study area (Figs. 3 

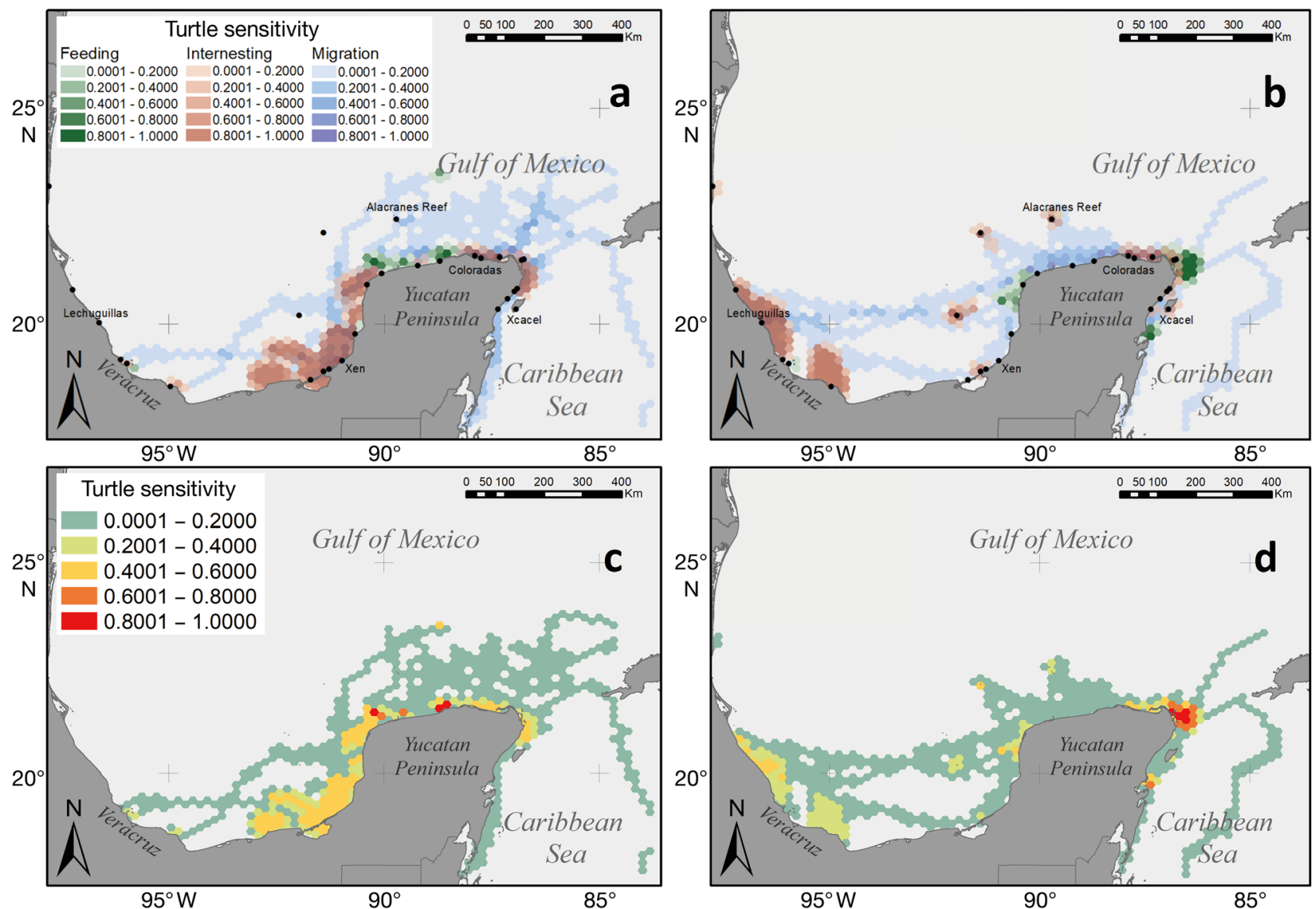

Fig. 2. Spatial distribution of ecological sensitivity categorized by life cycle stage for both (a) hawksbill and (b) green turtles in the southern Gulf of Mexico. Maps in (c) and (d) represent the spatial integration of the 3 sensitivity stages (feeding, internesting aggregations and migratory corridors)

\& S1) were quantified. Because both species' distributions were mainly concentrated on the continental shelf, most of the interaction zones and those with the highest intensities were in this area. These species have benthic feeding habits so it was expected to find them in areas on the continental shelf (Spotila 2004). As Uribe-Martínez et al. (2017) reported, both hawksbills and green turtles widely use the continental shelf in the southern Gulf of Mexico throughout their entire life cycle, as it contains the critical habitats they require throughout their life.

As derived from the analytic hierarchy process for threat-weighting based on expert knowledge (Table 2 ), the greatest threat was identified as fishing effort $(\mu=0.481)$, followed by increases in average SST $(\mu=$ $0.142)$, the occurrence of hurricanes $(\mu=0.118)$, cargo vessel transit $(\mu=0.116)$, impacts from oil extraction platforms $(\mu=0.088)$ and the effects of seismic surveys $(\mu=0.054)$ (consistency ratio $=0.37$, geometry consistency index $=0.07$, eigenvector method check $=6.2 \mathrm{E}^{-08}$, consensus $=81.1 \%$ ).
The sea turtle aggregations in Veracruz were mainly affected by fishing effort; further, the sensitive areas in the Yucatan Channel (located between the northeastern corner of the Yucatan peninsula and western Guanahacabibes peninsula, Cuba) were impacted by hurricanes, cargo vessel transit and the increases in SST (Fig. 3).

\subsection{Stability coefficient features}

Given the nature of the 2 extrinsic stability coefficient indicators (NPAs and safeguards), their total influence was distributed over the continental shelf in the southern Gulf of Mexico (Fig. 4, Table S1). Additionally, the intrinsic indicators (nesting population trends) were mostly distributed in the same region because the study species have benthic habitats, and the nesting trends at the same nesting beaches where we tracked the females were quantified for this variable. 
a) Hawksbill turtles
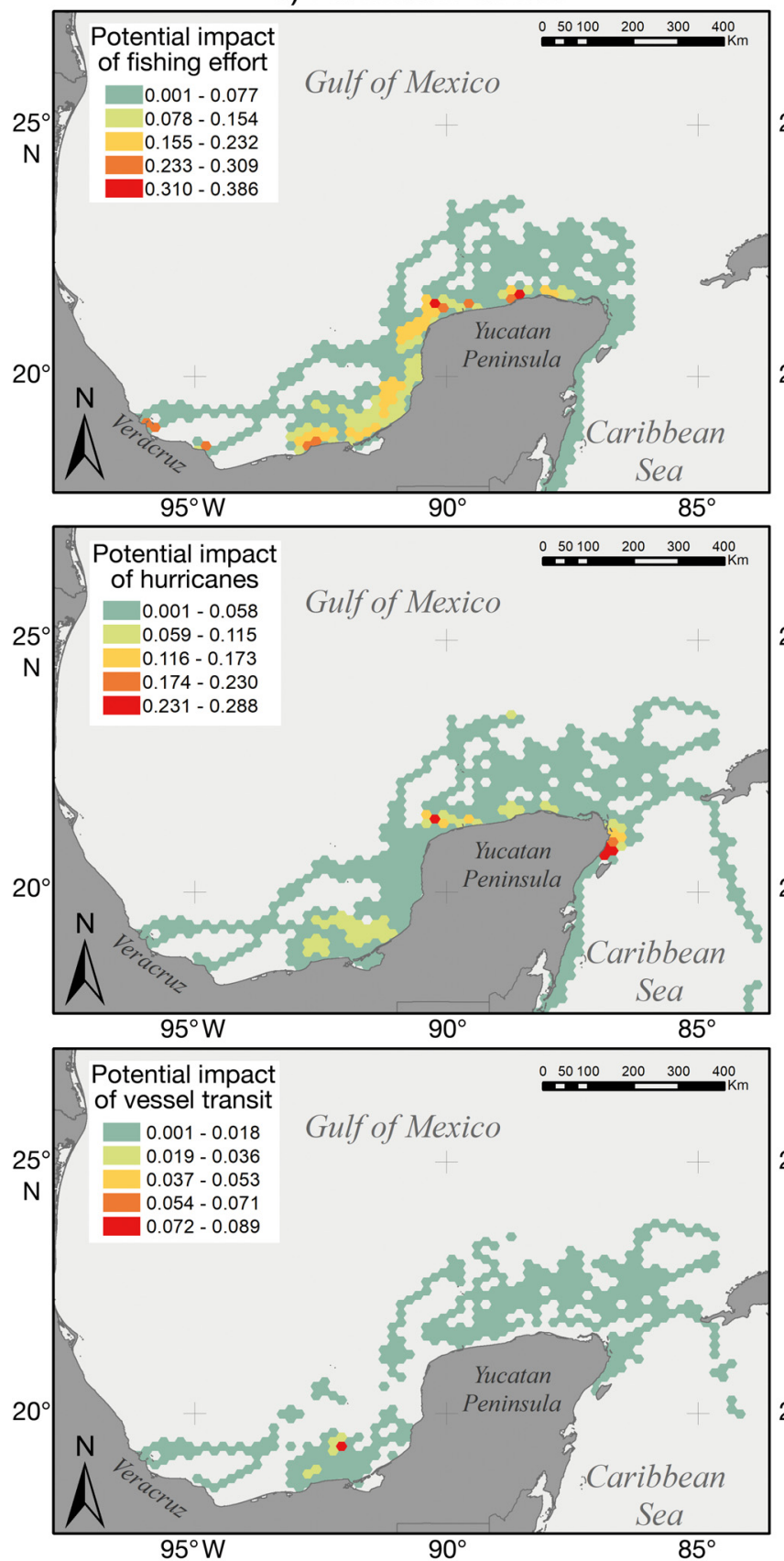

b) Green turtles
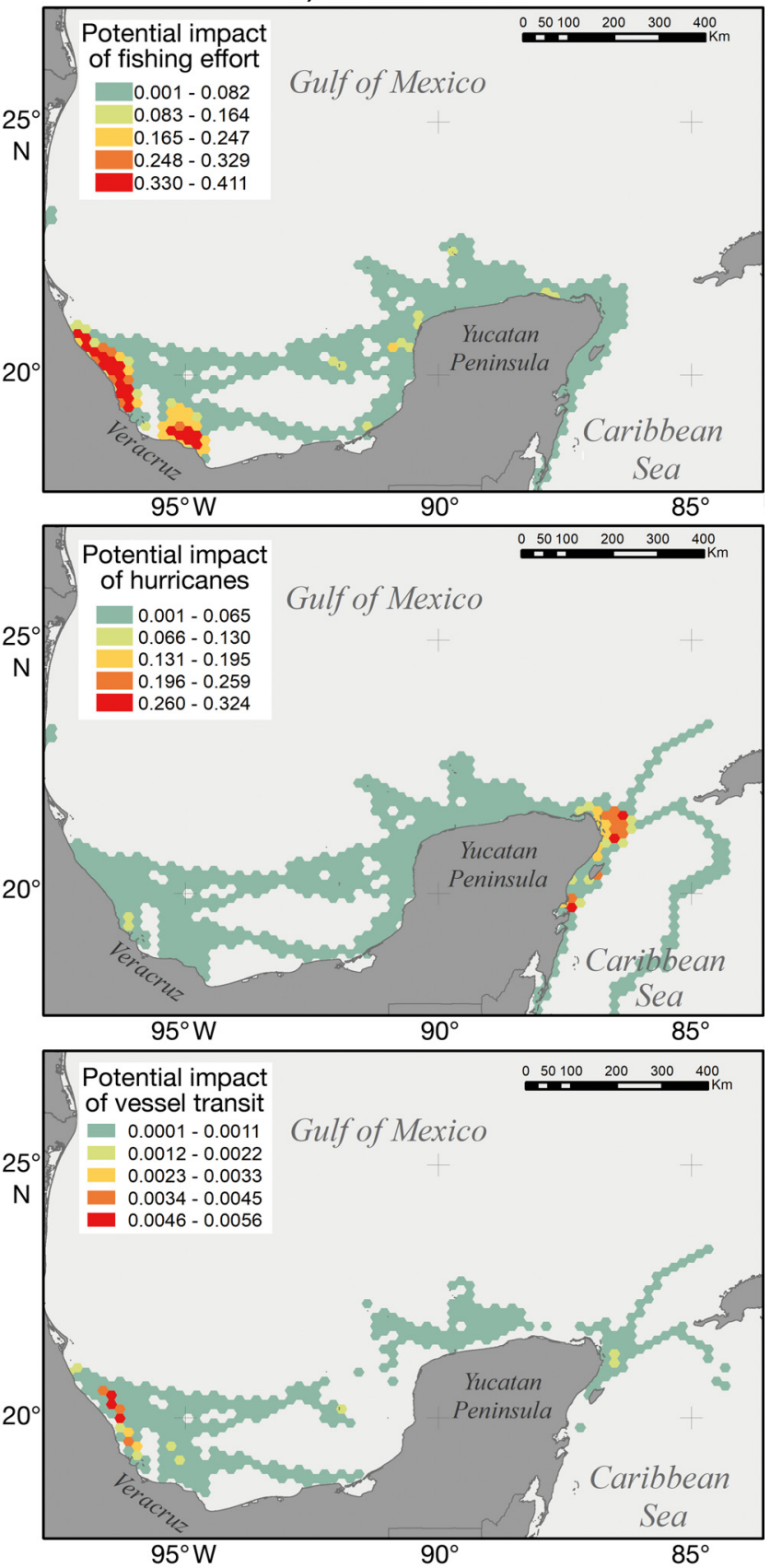

Fig. 3. Potential impacts of 3 different threats (fishing effort, occurrence of hurricanes and cargo vessel transit) on (a) hawksbill and (b) green turtles in the southern Gulf of Mexico

\subsection{Cumulative vulnerability for each OI}

After integrating all vulnerabilities, the spatial configuration of the cumulative vulnerability showed the highest values near Veracruz for both species, as well as for some areas around the Yucatan Peninsula that coincided with the zones mentioned in the sub-sections above (Fig. 5).

\subsection{Total cumulative vulnerability}

Ultimately, the spatial configuration of the total cumulative vulnerability revealed the assemblage for the 2 species, displaying the sum of the most vulnerable zones for each species and highlighting those zones where both species occur (Fig. 6). The most vulnerable zones for these species are located on the 

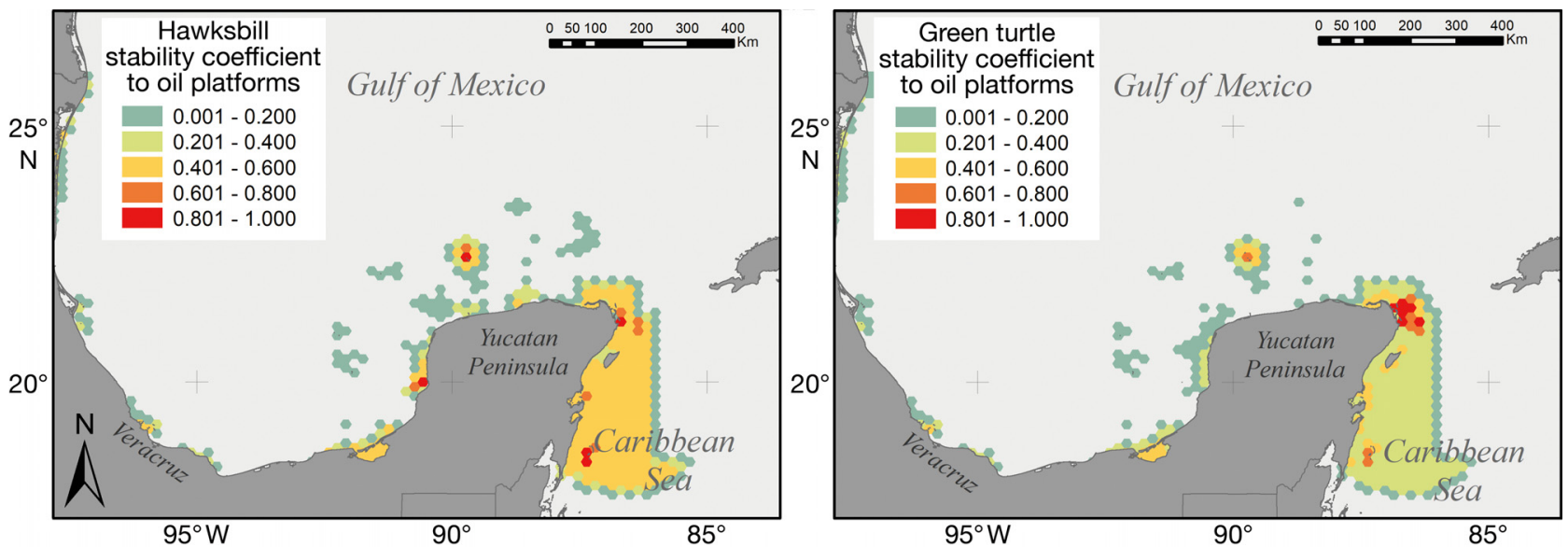

Fig. 4. Stability coefficient maps for threats to sea turtles from oil extraction platforms, derived from the integration of 3 indicators (natural protected areas, safeguards and sea turtle population trends). The latter indicator was specifically associated with nesting hawksbill and green turtle populations in the region. Together, the stability coefficients had a maximum reduction of

$35 \%$ of the impact caused by their respective threats
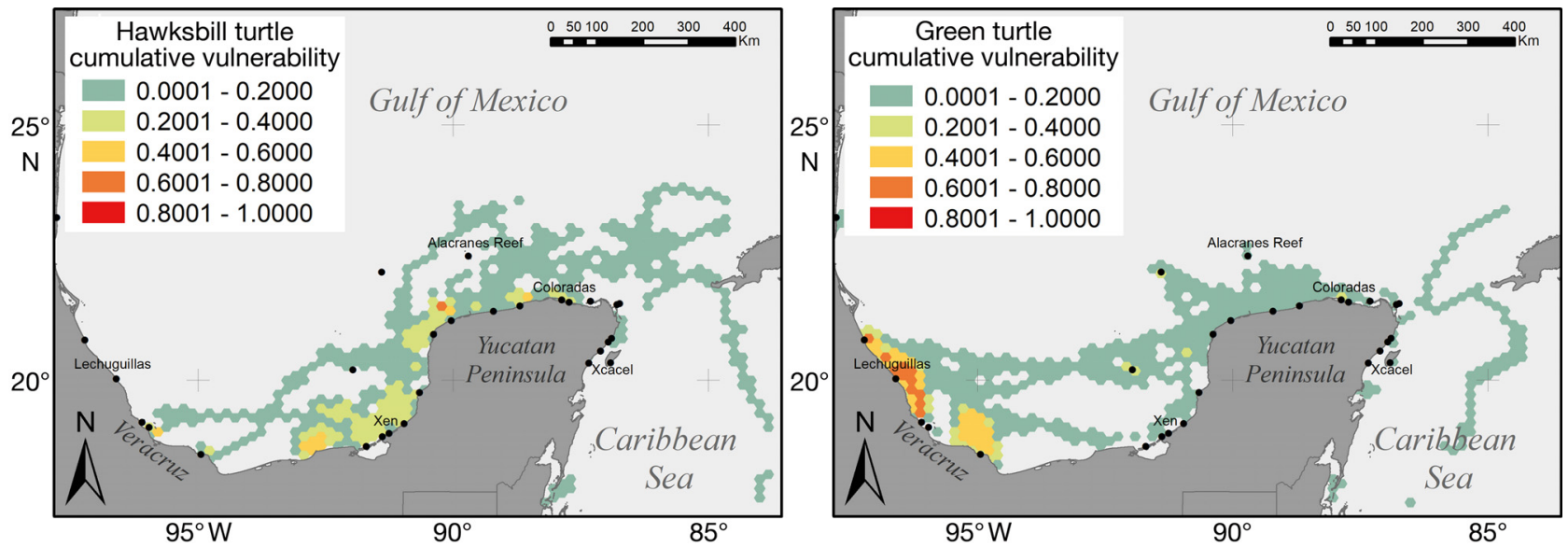

Fig. 5. Spatial configuration of the cumulative vulnerability to 6 different threats for hawksbill and green sea turtles in the southern Gulf of Mexico

continental shelf, where all 3 components of the vulnerability equation occur. Some zones were identified where vulnerability was equal to zero due to the action of the stability coefficient.

\subsection{Variance in ecological vulnerability}

After running the 30 different weighting scenarios for the major threat (fishing effort), the general spatial configuration of the cumulative ecological vulnerability for green turtles was preserved, with the median and third-quarter values remaining stable throughout the test, and maximum values slightly increasing during the experiment (Fig. 7). Although quantitative variations occurred in the spatial configurations of the ecological vulnerability assessment, the standard deviation in the core critical areas remained less than 0.06 (Fig. 7E).

\section{DISCUSSION}

\subsection{Methodological approach}

It has been well documented that the use of open source planning tools in conjunction with spatial products, such as remote sensing images and other continuous surface inputs, provides a robust framework for landscape-scale analyses (Carr et al. 


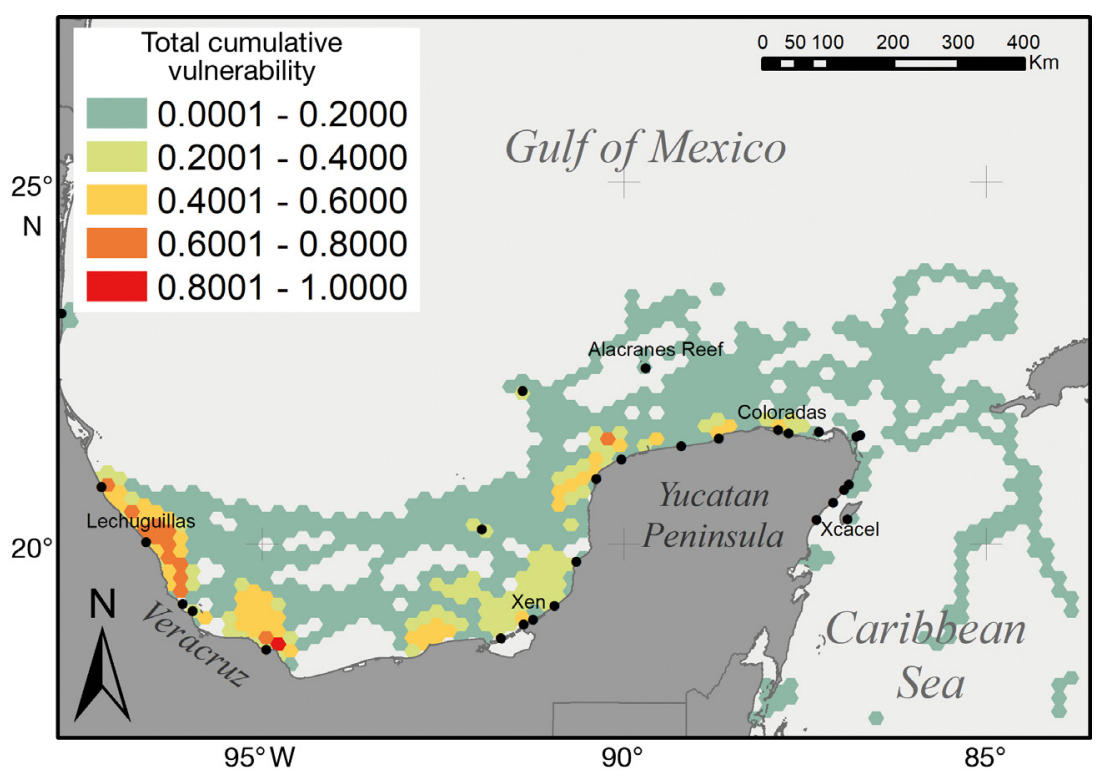

Fig. 6. Spatially explicit representations of the total cumulative vulnerability of hawksbill and green turtles to 6 different threats in the Gulf of Mexico

for optimization of results; however, since the results come from hard data and expert opinions, we assumed that they accurately represent the spatial configuration of vulnerability. These points are important because such uncertainty assessment will contribute to better decision making criteria and strengthen the spatially explicit outputs that are provided by this approach.

A key contribution of this approach is the evaluation of an integrated suite of threats, as recommended by Schwartz et al. (2017), to improve the understanding of conservation and management barriers. In conjunction with the spatially explicit products, this approach identifies locations where actions must be implemented in order to mitigate the impacts of a potential threat. For instance, our

2017). Integrating tools from different frameworks, including hard data enriched by expert knowledge for explicit outputs, strongly enhances research and the implementation of actions for conservation and strategic assessments (Hays et al. 2019, Salafsky et al. 2019), such as the one implemented in this study.

The CAP tool provides such support, and it has been used at numerous scales within several stakeholder sectors (Carr et al. 2017). In contrast with other existing evaluation frameworks, our approach using the CAP tool integrates strategic planning activities and outcomes in a systematic process that enables it to be combined with other methods, particularly spatial analysis (Carr et al. 2017). As a contribution to conservation, management and vulnerability assessments, we addressed one of the limitations of the CAP tool - insufficient explicit spatial capabilities - by assembling tabular information with spatially explicit procedures for completing landscapescale analyses. This contribution also explores one of the future directions identified for CAP tool analyses, as it uses well-known and simple transferable tools for spatial analysis.

One important drawback to this tool is that additional input data and homologous vulnerability information are rarely available to quantitively evaluate accuracy and uncertainty, other than the expert opinion of specialists. For the approach presented in this study, a more detailed validation procedure for the final outputs and sensitivity analysis is still needed results are useful as a basis for oil spill and climate change risk assessments and the evaluation of spatial assemblages between species and life stages, among others.

Several other approaches are available in the literature that can be used to evaluate the ecological vulnerability and sensitivity of coastal ecosystems and species. One approach is the environmental sensitivity index (Jensen et al. 1998), which was developed as an administrative response to oil spills off US coasts. This index evaluates the sensitivity of the ecosystems to a threat (i.e. oil spills), but it is restricted to only evaluating the sensitivity of the OI. The environmental sensitivity index has been widely used and is a good tool for efficient planning (Helle et al. 2016, Nelson \& Grubesic 2017); however, from our perspective, it lacks some precision in terms of the technical and ecological information of the attributes and the criteria for each term in the evaluation (sensitivity, threats).

The equations that were adopted and modified for our approach allow any number of input variables to be included for each term, such as the number of OIs and their ecological attributes, threats and stability coefficients. Additionally, this spatial analysis strategy allows variables to be taken from different sources with a variety of spatial resolutions and scales and then transforms these variables to common spatial terms (Maxwell et al. 2013, Stokes et al. 2015).

Schumaker (2016) offers a complete and powerful tool (HexSim) that utilizes a spatial approach similar 

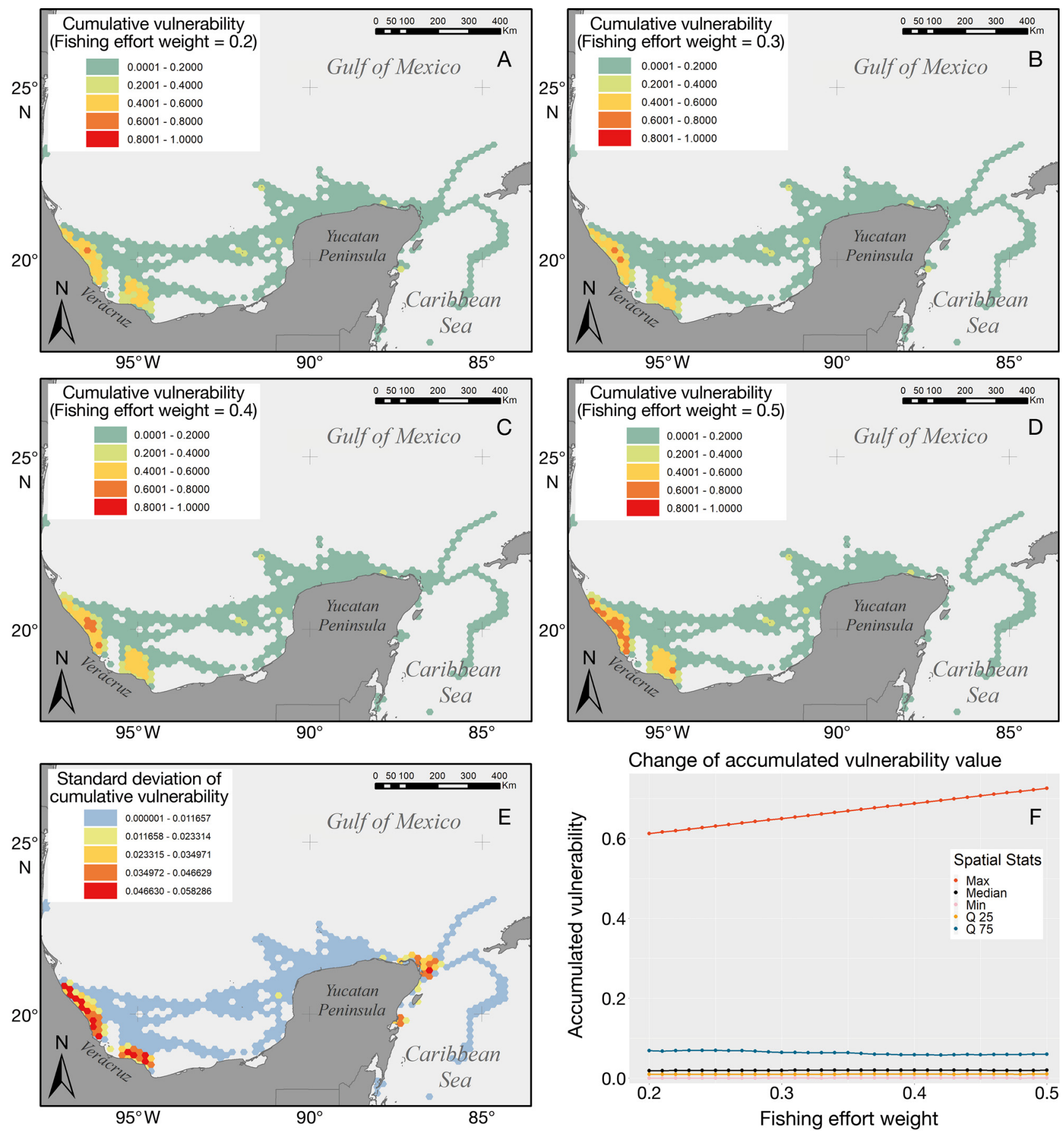

Fig. 7. (A-D) Spatial configuration of cumulative ecological vulnerability for green turtles under 4 different weighting values for the main identified threat: fishing effort. (E) Standard deviation of ecological vulnerability quantification using 30 different weighting values for fishing effort mapped for both sea turtle species (hawksbill and green turtles), and (F) central and dispersion statistics are kept stable throughout the experiment

to ours; however, the conceptual framework of HexSim assumes that all the required quantitative input data are well accommodated in the spatial realm. In the absence or in the case of poor quantitative and geographic data, which is common in lesser developed countries, our method has the advantage of allowing manually curated and expert knowledge to be used in the model.

Love et al. (2017) and Hart et al. (2018) assessed a spatially explicit impact score for Kemp's ridley Lepidochelys kempii and loggerhead turtles Caretta caretta after combining different in-water and terres- 
trial threats in the northern Gulf of Mexico. While this assessment is comparable to the potential impact maps that we obtained, the numerical and conceptual approach differs in that it considers only one species at a time and does not include all the terms specified by the ecological vulnerability formula.

While we maintained a minimum level of complexity, our analyses were sufficiently robust to respond to conservation questions; we considered the scientific approach used by the conservation stakeholders to make decisions. Consequently, we increased the utility of our final products, while retaining the complete vulnerability assessment framework as well as a multi-species approach. Such conditions will increase the probability that this model will be adopted by decision makers and environmental authorities instead of being restricted to strict scientific evaluation (Schwartz et al. 2017). With the approach presented here, even in circumstances of poor quantitative data, we can provide spatially explicit information to sustain more robust and effective management and policy decisions. Some management tasks that could be accomplished are the definition of closure zones (nofishing reserves, marine protected areas) and biodiversity hotspots, among others.

\subsection{Spatially explicit ecological vulnerability of sea turtles}

This study is the first spatially explicit assessment of the ecological vulnerability of sea turtle species to multiple threats in Mexican waters, and it acts as a baseline reference for future evaluations and monitoring of other species and groups to better represent the biodiversity in this oceanic watershed. It also provides a framework for comparative or contrasting studies

With the results obtained here, by incorporating the 3 components of the vulnerability assessment, we provide decision makers, scientists and any stakeholder involved in sea turtle conservation and management with reference information for regional and landscape strategies for the conservation and management of sea turtles (i.e. international cooperation, feedback for regional management units, wider vision for strategic planning for long-term financing). It was important that we derived spatially explicit information about specific threats occurring in the most important sea turtle in-water habitats in the southern Gulf of Mexico.

The in-water habitats for sea turtles represent a challenge for any ecological assessment because of the large information gaps that exist for individual sea turtles and the threats they face in marine areas. In this assessment, information about the spatial distribution of 2 sea turtle species was available, and the spatial occurrence of threats was gathered from different sources.

The zones near Veracruz as well as those in the southwest, northwest and northeast corners of the Yucatan Peninsula are of interest because they have important aggregations of multiple individuals, and some of the major potential impacts caused by the threats occur in those zones. For several of those threats, there was no literature available that provided spatially explicit information, so we present information that is completely new for the southern Gulf of Mexico in this study, including the intermediate outputs (i.e. the spatial configuration of fishing effort). Given the information gaps, it is difficult to find similar spatially explicit products with which to compare our results.

The calculation of kernel utilization distributions (KUD) for marine animals is a common practice in threat and ecological vulnerability assessments. Here, we used it as an indicator of ecological attributes for hawksbill and green sea turtles, and the results were consistent with those of other studies. For instance, Fossette et al. (2014) used density maps from tracking-duration-weighted location data as the sensitive attribute of leatherbacks Dermochelys coriacea exposed to longline fisheries in the Atlantic. We decided to use the KUD because this quantitative variable provides more traceable information for the interpretation of potential impacts (derived from sensitive attributes exposed to a threat) (Thiault et al. 2018).

Quantitative weighting for different threats is a common practice in spatial multi-criteria analyses as well as in ecological and social vulnerability assessments (Saaty 2008, He et al. 2018). This practice is consistent with our approach of weighting the threats according to their intensity, scope and irreversibility. The weighting values used in this study were supported by specialized literature and expert knowledge, but one of the advantages of the conceptual framework and the approach used in this analysis is that the user can adjust and define the values that they consider most appropriate, enabling the evaluation of different weighting scenarios for the variables. However, in terms of the potential impacts of the 6 threats evaluated here, sea turtle bycatch (with its origin in fishing effort and inappropriate fishing practices) is considered one of the greatest threats to these species worldwide (Lewison et al. 2014, Squires et al. 2018), so it is not unusual that the specialists scored this as the top threat. 
In the southern Gulf of Mexico, some studies have assessed the impacts of sea turtle bycatch, and Cuevas et al. (2018a) noted the same zones around the Yucatan Peninsula as the most threatening areas for sea turtles. As this threat had the greatest weight at several sites in the present study, the occurrence of high levels of fishing effort (with its corresponding high weight) strongly defines the high vulnerability values, particularly when it is also present alongside other threats.

Ban et al. (2010) reported similar magnitudes of differences between the assigned weight for fishing effort and the remaining threats they evaluated on the western coast of Canada. They used a weight value for fishing effort that tripled the value of the next greatest threat (3.38), which was similar to the value used in this study for fishing effort. As multiple threats often act on the OI, it could be expected that one or a few threats drive an important portion of the process; however, the rest of the factors also contributed to modeling the final configuration of the evaluated system.

After quantifying the variance in cumulative ecological vulnerability under 30 different fishing effort values, the core spatial configuration of the calculation remained consistent. The variability graph and maps constructed here provide important reference tools for sustaining the spatially explicit products presented in this analysis.

In the case of the increasing average SST, climatic variables can affect the phenology, distribution range, trophic status and nesting seasons of sea turtles around the world (Broderick et al. 2001, James et al. 2006, Patel et al. 2016). Uribe-Martínez et al. (2017) showed that an increase in SST would modify the spatial configuration of suitable habitat for Chelonia mydas and Eretmochelys imbricata in the southern Gulf of Mexico, so important consideration in this region should be given to the threat of increased SST to sea turtle aggregations.

Micheli et al. (2013) identified oceanic environment variables as major threats for marine ecosystems, assuming the potential impacts of variables such as pH decreases, as well as SST and UV increases. Although that study did not focus on sea turtle populations, the concern the authors express about these threats is similar to the basic reasons why variables such as SST increases are of concern for sea turtles, since these are elements of the marine ecosystems they evaluated.

The southern Gulf of Mexico and the western Caribbean are regions with a high incidence of hurricanes, and the impacts of these hydrometeorological phenomena on sea turtle populations and habitats are well documented (Pike \& Stiner 2007, Dewald \& Pike 2014, Bilskie et al. 2016, Wilson et al. 2017). Most of the impacts from hurricanes occur on the east side of the Yucatan Peninsula, and this threat was considered; however, its weight was not significant enough to drive the spatial configuration of the total cumulative vulnerability.

Along the Quintana Roo coast, which is also on the east side of the Yucatan Peninsula, fishing effort is practically absent because the area is primarily used for tourism. Other threats such as the occurrence of hurricanes and increasing SSTs impact this zone, but the weights given to these threats were much lower than that given to fishing effort. Furthermore, the protection in this area provided by NPAs and safeguards apparently ensure that the stability coefficient is sufficient for mitigating the exposure to these threats. This information does not mean that in-water aggregations of sea turtles in Quintana Roo are not under pressure. At this geographic scale and with the variables included in this assessment, the in-water habitats in this area are less vulnerable than those in areas in Campeche and Veracruz (southern Gulf of Mexico), where the cumulative impacts on the aggregations are much higher. However, attention to more local in-water threats such as benthic habitat degradation should be considered for the recovery of these species and the maintenance of the ecosystems they occupy in Quintana Roo; although the regional context is also important for these highly migratory species.

We are aware that there are other in-water threats to sea turtles and their habitats (e.g. pollution, habitat degradation because of land runoffs, red tides, diseases); during the workshop with experts some of these threats were stipulated, but were ranked with minor grades (data not shown), reinforcing the information contained int the National Recovery Plans for both green and hawksbill turtles (Comisión Nacional de Áreas Naturales Protegidas 2009, 2011) that we also took into account for defining the threats in this study. For instance, an assessment of the impact of tourism was beyond the scope of this work, and it is possible that overdeveloped touristic regions may show different trends in the vulnerability of nesting beaches.

Although we would expect that the inclusion of additional threats in this analysis could change the spatial configuration of ecological vulnerability of these species, the threats used for this analysis were ranked as the top 6, and spatial information for them was available for this assessment. On the other hand, for the evaluated region there was no spatially explicit information on the other in-water threats nor 
were they highlighted as being issues of concern. This analysis is a baseline and could be considered a platform for the detection of such data/information gaps that should be included in a spatially explicit evaluation, and in subsequent analyses and updates, we will work to identify proxies and data sources for those threats without explicit spatial information for a complete assessment as in this study.

Consistent with several other studies (Wallace et al. 2010, Maxwell et al. 2013, 2015), the spatially explicit information presented here contributes key knowledge to marine spatial planning. The results of this study aid in the implementation of specific strategies for conservation, management and policy for the recovery of other endangered species (i.e. other sea turtle species, marine mammals, sea birds, large fishes) in the Large Ecosystem of the Gulf of Mexico.

This study presents a utility model and an example of the application of an open source planning tool (the CAP tool) combined with standardized protocols as well as spatial analyses based on multi-criteria rationale. The resulting approach can be characterized by its feasibility and replicability for other environmental systems.

Acknowledgements. This work was supported by the Hydrocarbon Fund of the National Council for Science and Technology (SENER-CONACyT Hidrocarburos) project No. 201441 ; the funding source did not participate in the design of this assessment. This study is part of project No. 201441 'Implementation of oceanographic observation networks (physical, geochemical, ecological) to generate scenarios in the face of possible contingencies related to hydrocarbon exploration and production in the deep waters of the Gulf of Mexico'. We also thank the Dirección General de Vida Silvestre from the Secretaría de Medio Ambiente y Recursos Naturales de México for the Permit to track sea turtle individuals from nesting beaches (No. SGPA/DGVS/03989/17). We thank S. Gallegos, P. García, G. Mexicano, E. Palafox and $\mathrm{H}$. Hernández for their hard work on the acquisition of telemetry data during the field campaigns. Special thanks go to E. Castro for the data extraction work related to threats and the preparation of some supplementary material. We are particularly grateful to the Mexican sea turtle experts in the Gulf of Mexico and Caribbean Sea, who responded to the threat weighting survey in June 2018, and to the reviewers for the comments and suggestions to improve the manuscript.

\section{LITERATURE CITED}

Adger WN (2006) Vulnerability. Glob Environ Change 16: $268-281$

Álvarez-Acosta A (2016) Influencia de la temperatura superficial del mar sobre la fenología reproductiva de la tortuga carey (Eretmochelys imbricata) en playas índice de la península de Yucatán, México. MSc dissertation, Research Center and Advanced Studies of the National Polytechnique Institute, Merida
Arellano-Méndez LU, Liceaga-Correa MA, Herrera-Silveira JA, Hernández-Núñez H (2011) Impacto por huracanes en las praderas de Thalassia testudinum (Hydrocharitaceae) en el Caribe Mexicano. Rev Biol Trop 59: 385-401

Ban NC, Alidina HM, Ardron JA (2010) Cumulative impact mapping: advances, relevance and limitations to marine management and conservation, using Canada's Pacific waters as a case study. Mar Policy 34:876-886

*Beever EA, O'Leary J, Mengelt C, West JM and others (2016) Improving conservation outcomes with a new paradigm for understanding species' fundamental and realized adaptive capacity. Conserv Lett 9:131-137

Bilskie MV, Hagen SC, Alizad K, Medeiros SC, Passeri DL, Needham HF, Cox A (2016) Dynamic simulation and numerical analysis of hurricane storm surge under sea level rise with geomorphologic changes along the northern Gulf of Mexico. Earths Future 4:177-193

Birch CPD, Oom SP, Beecham JA (2007) Rectangular and hexagonal grids used for observation, experiment and simulation in ecology. Ecol Modell 206:347-359

* Bouchard SS, Bjorndal KA (2000) Sea turtles as biological transporters of nutrients and energy from marine to terrestrial ecosystems. Ecology 81:2305-2313

* Broderick AC, Godley BJ, Hays GC (2001) Trophic status drives interannual variability in nesting numbers of marine turtles. Proc R Soc B 268:1481-1487

* Broderick AC, Coyne MS, Fuller WJ, Glen F, Godley BJ (2007) Fidelity and over-wintering of sea turtles. Proc R Soc B 274:1533-1538

Calenge C (2006) The package adehabitat for the R software: a tool for the analysis of space and habitat use by animals. Ecol Modell 197:516-519

Carr B, Fitzsimons J, Holland N, Berkinshaw T and others (2017) CAPitalising on conservation knowledge: using Conservation Action Planning, healthy country planning and the open standards in Australia. Ecol Manage Restor 18:176-189

Christie P, White AT (2007) Best practices for improved governance of coral reef marine protected areas. Coral Reefs 26:1047-1056

* Comisión Nacional de Acuacultura y Pesca (2014) Anuario Estadístico de Acuacultura y Pesca 2014. https://www. gob.mx/conapesca/documentos/anuario-estadistico-deacuacultura-y-pesca (accessed 15 August 2018)

Comisión Nacional de Áreas Naturales Protegidas (2009) Programa de Acción para la Conservación de la Especie Eretmochelys imbricata. Secretaría de Medio Ambiente y Recursos Naturales https://www.gob.mx/cms/uploads/ attachment/file/350214/PACE_Tortuga_Carey.pdf (accessed 15 Aug 2018)

Comisión Nacional de Áreas Naturales Protegidas (2011) Programa de Acción para la Conservación de la Especie Chelonia mydas. Secretaría de Medio Ambiente y Recursos Naturales, Mexico. www.conanp.gob.mx/conanp/ dominios/especies/WEB/docs/pace/PACE-TORTUGAVERDE-NEGRA.pdf (accessed 15 Aug 2018)

Comisión Nacional de Hidrocarburos (2017a) Pozos y Licitaciones del Portal de información técnica v2.1.4. $2017 \mathrm{a}$. https://portal.cnih.cnh.gob.mx/estadisticas.php (accessed 15 August 2018)

* Comisión Nacional de Hidrocarburos (2017b) Áreas contractuales a través de las Rondas sujetas a concurso por licitación. https://portal.cnih.cnh.gob.mx/iicnih/?lng=es_MX (accessed 15 August 2018) 
Comisión Nacional de Hidrocarburos (2017c) Zonas Sísmicas 2D y 3D. 2017c. https://portal.cnih.cnh.gob.mx/ iicnih/?lng=es_MX (accessed 15 August 2018)

Cuevas E (2004) Caracterización especial y detección de cambio, por el paso del huracán Isidoro, de los hábitats submarinos en el oriente del estado de Yucatán, México. MSc dissertation, Research Center and of Advanced Studies of the National Polytechnique Institute, Merida

Cuevas E, Guzmán-Hernández V, Uribe-Martínez A, Raymundo-Sánchez A, Herrera-Pavón R (2018a) Identification of potential sea turtle bycatch hotspots using a spatially explicit approach in the Yucatan Peninsula, Mexico. Chelonian Conserv Biol 17:78-93

* Cuevas E, Guzmán-Hernández V, Sarti-Martínez AL, López-Castro $M$ and others (2018b) Mexico. In: Nalovic M, Cuevas E, Godfrey M (eds) Sea turtles in the north-west Atlantic and Caribbean region. Draft Report of the IUCN-SSC Marine Turtle Specialist Group. IUCN, Gland

Dalton T, Jin D (2010) Extent and frequency of vessel oil spills in US marine protected areas. Mar Pollut Bull 60: 1939-1945

del Corral-Mancera M (2016) Estructura genética de las colonias de tortuga verde (Chelonia mydas) en el Golfo y Caribe mexicano estudiada por medio de microsatélites en la región control del DNA mitocondrial. MSc dissertation, National Autonomous University of Mexico, Mazatlán

Dewald JR, Pike DA (2014) Geographical variation in hurricane impacts among sea turtle populations. J Biogeogr 41:307-316

Diario Oficial de la Federación (2012) Acuerdo por el que se da a conocer la Actualización de la Carta Nacional Pesquera. https://www.inapesca.gob.mx/portal/documentos/ publicaciones/CARTA\%20NACIONAL\%20PESQUERA/ 24082012\%20SAGARPA.pdf (accessed 15 August 2018)

Diario Oficial de la Federación (2014) Reglamento de la Ley General del Equilibrio Ecológico y la Protección al Ambiente en Materia de Áreas Naturales Protegidas. www. diputados.gob.mx/LeyesBiblio/regley/Reg_LGEEPA_A NP.pdf (accessed 15 August 2018)

Diario Oficial de la Federación (2016) Quinta Sección, Poder Ejecutivo, Secretaría de Energía. Decreto por el que se establece la zona de salvaguarda denominada Arrecifes de Coral del Golfo de México y Caribe Mexicano. www. dof.gob.mx/nota_detalle.php? codigo $=5464472 \&$ fecha $=0$ 7/12/2016 (accessed 15 August 2018)

Eckert KL, Hemphill AH (2005) Sea turtles as flagships for protection of the wider Caribbean region. Marit Stud 4: 119-143

Fossette S, Witt MJ, Miller P, Nalovic MA and others (2014) Pan-Atlantic analysis of the overlap of a highly migratory species, the leatherback turtle, with pelagic longline fisheries. Proc R Soc B 281:20133065

Frazier J (2005) Marine turtles: the role of flagship species in interactions between people and the sea. Marit Stud 3-4: $5-38$

Freitas C, Lydersen C, Ims RA, Fedak MA, Kovacs KM (2008) A simple new algorithm to filter marine mammal Argos locations. Mar Mamm Sci 24:315-325

French CD, Schenk JS (2015) Shaded relief image of the Gulf of Mexico. US Geological Survey, Central Energy Resources Team. https://pubs.er.usgs.gov/publications/ ofr97470L (accessed 15 Aug 2018)
Fuentes MMPB, Abbs D (2010) Effects of projected changes in tropical cyclone frequency on sea turtles. Mar Ecol Prog Ser 412:283-292

Fuentes MMPB, Limpus CJ, Hamann M (2011) Vulnerability of sea turtle nesting grounds to climate change. Glob Change Biol 17:140-153

炎Füssel HM, Klein RJT (2006) Climate change vulnerability assessments: an evolution of conceptual thinking. Clim Change 75:301-329

*Gaos AR, Lewison RL, Jensen MP, Liles MJ and others (2017) Natal foraging philopatry in eastern Pacific hawksbill turtles. R Soc Open Sci 4:170153

Garduño-Andrade M, Guzmán V, Miranda E, Briseno-Duenas R, Abreu-Grobois FA (1999) Increases in hawksbill turtle (Eretmochelys imbricata) nestings in the Yucatán Peninsula, Mexico, 1977-1996: Data in support of successful conservation? Chelonian Conserv Biol 3:286-295

Goepel KD (2013) Implementing the analytic hierarchy process as a standard method for multi-criteria decision making in corporate enterprises - a new AHP Excel template with multiple inputs. Proc Int Symp Analytic Hierarchy Process 2013:1-10. Creative Decisions Foundation, Kuala Lumpur

*González Garza BI, Stow A, Sánchez-Teyer LF, ZapataPérez O (2015) Genetic variation, multiple paternity, and measures of reproductive success in the critically endangered hawksbill turtle (Eretmochelys imbricata). Ecol Evol 5:5758-5769

Granizo T, Molina ME, Secaira E, Herrera B and others (2006) Manual de Planificación para la Conservación de Áreas, PCA, 1st edn. The Nature Conservancy/USAID, Quito

*Halpern BS, Walbridge S, Selkoe KA, Kappel CV and others (2008) A global map of human impact on marine ecosystems. Science 319:948-952

*Halpern BS, Frazier M, Potapenko J, Casey KS and others (2015) Spatial and temporal changes in cumulative human impacts on the world's ocean. Nat Commun 6:7615

Hamann M, Fuentes MMPB, Ban NC, Mocellin VJL (2013) Climate change and marine turtles. In: Wyneken J, Lohman KJ, Musick JA (eds) The biology of sea turtles, Vol 3. CRC Press, Boca Raton, FL, p 353-378

*Hart KM, Iverson AR, Fujisaki I, Lamont MM, Bucklin D, Shaver DJ (2018) Marine threats overlap key foraging habitat for two imperiled sea turtle species in the Gulf of Mexico. Front Mar Sci 5:336

*Hawkes LA, Broderick AC, Godfrey MH, Godley BJ (2009) Climate change and marine turtles. Endang Species Res $7: 137-154$

*Hays GC, Hawkes LA (2018) Satellite tracking sea turtles: opportunities and challenges to address key questions. Front Mar Sci 5:432

Hays GC, Bailey H, Bograd SJ, Don-Bowes W and others (2019) Translating marine animal tracking data into conservation policy and management. Trends Ecol Evol 34: 459-473

*He L, Shen J, Zhang Y (2018) Ecological vulnerability assessment for ecological conservation and environmental management. J Environ Manage 206:1115-1125

Heithaus MR (2013) Predators, prey, and the ecological roles of sea turtles. In: Wyneken J, Lohman KJ, Musick JA (eds) The biology of sea turtles, Vol 3. CRC Press, Boca Raton, FL, p 249-284

*Helle I, Jolma A, Venesjärvi R (2016) Species and habitats in danger: estimating the relative risk posed by oil spills in the northern Baltic Sea. Ecosphere 7:e01344 
Heppell SS (1998) Application of life-history theory and population model analysis to turtle conservation. Copeia 1998:367-375

* Hu C, Li X, Pichel WG, Muller-Karger FE (2009) Detection of natural oil slicks in the NW Gulf of Mexico using MODIS imagery. Geophys Res Lett 36:L01604

* Hulin V, Guillon JM (2007) Female philopatry in a heterogeneous environment: ordinary conditions leading to extraordinary ESS sex ratios. BMC Evol Biol 7:13

Hyrenbach KD, Forney KA, Dayton PK (2000) Marine protected areas and ocean basin management. Aquat Conserv 10:437-458

Jackson JBC (1997) Reefs since Columbus. Coral Reefs 16(Suppl):S23-S32

James MC, Davenport J, Hays GC (2006) Expanded thermal niche for a diving vertebrate: a leatherback turtle diving into near-freezing water. J Exp Mar Biol Ecol 335: 221-226

Jeffers VF, Godley BJ (2016) Satellite tracking in sea turtles: How do we find our way to the conservation dividends? Biol Conserv 199:172-184

* Jensen JR, Halls JN, Michel J (1998) A systems approach to environmental sensitivity index (ESI) mapping for oil spill contingency planning and response. Photogramm Eng Remote Sensing 64:1003-1014

Labastida-Estrada E, Machkour-M'Rabet S, Díaz-Jaimes P, Cedeño-Vázquez JR, Hénaut Y (2019) Genetic structure, origin and connectivity between nesting and foraging areas of hawksbill turtles of the Yucatan Peninsula: a study for conservation and management. Aquat Conserv 29:211-222

* Lal A, Arthur R, Marbà N, Lill AWT, Alcoverro T (2010) Implications of conserving an ecosystem modifier: Increasing green turtle (Chelonia mydas) densities substantially alters seagrass meadows. Biol Conserv 143: 2730-2738

Lee PLM, Luschi P, Hays GC (2007) Detecting female precise natal philopatry in green turtles using assignment methods. Mol Ecol 16:61-74

* Lewison RL, Crowder LB, Wallace BP, Moore JE and others (2014) Global patterns of marine mammal, seabird, and sea turtle bycatch reveal taxa-specific and cumulative megafauna hotspots. Proc Natl Acad Sci USA 111: 5271-5276

Love M, Robbins C, Baldera A, Eastman S and others (2017) Restoration without borders: an assessment of cumulative stressors to guide large-scale, integrated restoration of sea turtles in the Gulf of Mexico. https://oceancon servancy.org/wp-content/uploads/2017/10/Restoration_ Without_Borders.pdf (accessed 15 August 2018)

Malczewski J (1999) GIS and multicriteria decision analysis, $1^{\text {st }}$ edn. John Wiley \& Sons, Hoboken, NJ

* Maxwell SM, Hazen EL, Bograd SJ, Halpern BS and others (2013) Cumulative human impacts on marine predators. Nat Commun 4:2688

Maxwell SM, Hazen EL, Lewison RL, Dunn DC and others (2015) Dynamic ocean: defining and conceptualizing real-time management of the ocean. Mar Policy 58:42-50

Mazaris AD, Schofield G, Gkazinou C, Almpanidou V, Hays GC (2017) Global sea turtle conservation successes. Sci Adv 3:e1600730

Mazor T, Beger M, McGowan J, Possingham HP, Kark S (2016) The value of migration information for conservation prioritization of sea turtles in the Mediterranean. Glob Ecol Biogeogr 25:540-552
McCarthy JJ, Canziani OF, Leary NA, Dokken DJ, White KS (2001) Climate change 2001: impacts, adaptation and vulnerability. Contribution of Working Group 2 to the $3^{\text {rd }}$ Assessment Report of the Intergovernmental Panel on Climate Change. Cambridge University Press, Cambridge

*Micheli F, Halpern BS, Walbridge S, Ciriaco S and others (2013) Cumulative human impacts on Mediterranean and Black Sea marine ecosystems: assessing current pressures and opportunities. PLOS ONE 8:e79889

Mortimer JA, Donnelly M (2008) Eretmochelys imbricata. The IUCN Red List of Threatened Species. IUCN SSC Marine Turtle Specialist Group 2008:e.T8005A12881238. http://doi.org/10.2305/IUCN.UK.2008.RLTS.T8005A128 81238.en (accessed 15 Aug 2018)

Nelms SE, Piniak WED, Weir CR, Godley BJ (2016) Seismic surveys and marine turtles: An underestimated global threat? Biol Conserv 193:49-65

Nelson JR, Grubesic TH (2017) A repeated sampling method for oil spill impact uncertainty and interpolation. Int $\mathrm{J}$ Disaster Risk Reduct 22:420-430

*NOAA (2017) Hurricanes and storms dataset; 2017. Database: storm: ftp://eclipse.ncdc.noaa.gov/pub/ibtracs/ v03r10/all/shp/ (accessed 15 Aug 2018)

Noguez Fuentes JF, Dreyfus León MJ, Robles Ruíz H (2007) Analysis of the long-line tune fishery in the Gulf of Mexico during the new and full moon phases. Hidrobiólogica 17:91-99

North MA (2009) A method for implementing a statistically significant number of data classes in the Jenks algorithm. In: Chen Y, Deng H, Zhang D, Xzio Y (eds) FSKD 2009: Proc $6^{\text {th }}$ Int Conf fuzzy systems and knowledge discovery, 14-16 Aug 2009, Tianjin. IEEE Computer Society, p 35-38

* OBPG (Ocean Biology Processing Group) (2016) MODIS Aqua level 3 SST MID-IR monthly $4 \mathrm{~km}$ nighttime, version 2014.0. PO.DAAC. http://dx.doi.org/10.5067/ MODAM-MO4N4 (accessed 15 Aug 2018)

* Parrish JD, Braun DP, Unnasch RS (2003) Are we conserving what we say we are? Measuring ecological integrity within protected areas. Bioscience 53:851-860

* Patel SH, Morreale SJ, Saba VS, Panagopoulou A, Margaritoulis D, Spotila JR (2016) Climate impacts on sea turtle breeding phenology in Greece and associated foraging habitats in the wider Mediterranean region. PLOS ONE 11:e0157170

* Patrício AR, Varela MR, Barbosa C, Broderick AC and others (2019) Climate change resilience of a globally important sea turtle nesting population. Glob Change Biol 25: 522-535

Pike DA, Stiner JC (2007) Sea turtle species vary in their susceptibility to tropical cyclones. Oecologia 153: 471-478

Reza MIH, Abdullah SA (2011) Regional index of ecological integrity: a need for sustainable management of natural resources. Ecol Indic 11:220-229

Saaty TL (2008) Decision making with the analytic hierarchy process. Int J Serv Sci 1:83-98

* Salafsky N, Boshoven J, Burivalova Z, Dubois NS and others (2019) Defining and using evidence in conservation practice. Conserv Sci Pract 1:e27

Sanderson EW, Redford KH, Vedder A, Coppolillo PB, Ward SE (2002) A conceptual model for conservation planning based on landscape species requirements. Landsc Urban Plan 58:41-56 
Sandivik B (2009) World Borders Dataset. http://thematicmapping.org/downloads/ (accessed 15 Aug 2018)

Schofield G, Dimadi A, Fossette S, Katselidis KA and others (2013) Satellite tracking large numbers of individuals to infer population level dispersal and core areas for the protection of an endangered species. Divers Distrib 19: 834-844

Schumaker NH (2016) HexSim version 3.1. US Environmental Protection Agency, Environmental Research Laboratory, Corvallis, OR. www.hexsim.net (accessed 10 Jan 2019)

Schwartz MW, Cook CN, Pressey RL, Pullin AS and others (2017) Decision support frameworks and tools for conservation. Conserv Lett 11:e12385

Scott R, Hodgson DJ, Witt MJ, Coyne MS and others (2012) Global analysis of satellite tracking data shows that adult green turtles are significantly aggregated in marine protected areas. Glob Ecol Biogeogr 21:1053-1061

Secretaría de la CIT (2010) Informe del 'Taller Regional sobre la Tortuga Carey en el Gran Caribe y el Atlántico Occidental'. Convención Interamericana para la Protección y Conservación de las Tortugas Marinas, Puerto Morelos

Servicio meteorológico nacional (2018) Etapas de Evolución-Ciclones tropicales Database: ciclones tropicales: http://smn.cna.gob.mx/es/ciclones-tropicales/etapas-deevolucion (accessed 15 Aug 2018)

Spotila JR (2004) Sea turtles: a complete guide to the biology, behavior, and conservation. The Johns Hopkins University Press, Baltimore, MD

Squires D, Restrepo V, Garcia S, Dutton P (2018) Fisheries bycatch reduction within the least-cost biodiversity mitigation hierarchy: conservatory offsets with an application to sea turtles. Mar Policy 93:55-61

Stiebens VA, Merino SE, Roder C, Chain FJJ, Lee PLM, Eizaguirre C (2013) Living on the edge: how philopatry maintains adaptive potential. Proc R Soc B 280:20130305

Stokes KL, Broderick AC, Canbolat AF, Candan O and others (2015) Migratory corridors and foraging hotspots: critical habitats identified for Mediterranean green turtles. Divers Distrib 21:665-674

*The Nature Conservancy (2015) Spatial CAP resources. http://conservationgateway.org/ConservationPlanning/ ActionPlanning/Guidance/Adaptations/SpatialCAPResources/Pages/spatial-cap-resources.aspx (accessed 15 Aug 2018)

Thiault L, Marshall P, Gelcich S, Collin A, Chlous F, Claudedt J (2018) Mapping social-ecological vulnerability to inform local decision making. Conserv Biol 32:447-456

Editorial responsibility: Richard Reina (Guest Editor), Melbourne, Victoria, Australia
Tolotti MT, Bach P, Hazin F, Travassos P, Dagorn L (2015) Vulnerability of the oceanic whitetip shark to pelagic longline fisheries. PLOS ONE 10:e0141396

* Tucker AD, Fitzsimmons NN, Limpus CJ (1995) Conservation implications of internesting habitat use by loggerhead turtles Caretta caretta in Woongarra Marine Park, Queensland, Australia. Pac Conserv Biol 2: 157-166

* Tulloch VJD, Tulloch AIT, Visconti P, Halpern BS and others (2015) Why do we map threats? Linking threat mapping with actions to make better conservation decisions. Front Ecol Environ 13:91-99

* Turner J, Klaus R (2005) Coral reefs of the Mascarenses, Western Indian Ocean. Philos Trans R Soc A 363:229-250

Uribe-Martínez A, Liceaga-Correa MA, Cuevas E (2017) Idoneidad ambiental de las tortugas marinas en el golfo de México: visión futura en un océano más caliente. In: Botello AV, Villanueva S, Gutiérrez J, Rojas-Galaviz JL (eds) Vulnerabilidad de las zonas costeras de Latinoamérica al cambio climático. UJAT, UNAM, UAC, Mexico City, p 395-430

* Valdivia A, Wolf S, Suckling K (2019) Marine mammals and sea turtles listed under the US Endangered Species Act are recovering. PLOS ONE 14:e0210164

Valverde RA, Holzwart KR (2017) Sea turtles of the Gulf of Mexico. In Ward SH (ed) Habitats and biota of the Gulf of Mexico: before the Deepwater Horizon oil spill, Vol 2. Springer-Verlag, New York, NY, p 1189-1352

Wallace BP, DiMatteo AD, Hurley BJ, Finkbeiner EM and others (2010) Regional management units for marine turtles: a novel framework for prioritizing conservation and research across multiple scales. PLOS ONE 5:e15465

Walters C (2000) Impacts of dispersal, ecological interaction, and fishing effort dynamics on efficacy of marine protected areas: How large should protected areas be? Bull Mar Sci 66:745-757

Wilkinson T, Wiken E, Bezaury-Creel J, Hourigan T and others (2009) Marine Ecoregions of North America. Commission for Environmental Cooperation, Québec

*Wilson M, Tucker AD, Beedholm K, Mann DA (2017) Changes of loggerhead turtle (Caretta caretta) dive behavior associated with tropical storm passage during the inter-nesting period. J Exp Biol 220:3432-3441

WWorton BJ (1989) Kernel methods for estimating the utilization distribution in home-range studies. Ecology 70 : 164-168

Zacharias MA, Gregr EJ (2005) Sensitivity and vulnerability in marine environments: an approach to identifying vulnerable marine areas. Conserv Biol 19:86-97

Submitted: February 21, 2019; Accepted: August 18, 2019 Proofs received from author(s): December 6, 2019 